\title{
Smouldering ashes: burning questions after the outbreak of electronic cigarette or vaping-associated lung injury (EVALI)
}

\author{
Gabor Zoltan Xantus (1), ${ }^{1}$ Anna V Gyarmathy, ${ }^{2,3}$ Carole Ann Johnson ${ }^{4}$
}

\begin{abstract}
${ }^{1}$ Alumnus at Critical Care Department, Cardiff University, Cardiff, UK

${ }^{2}$ Medical Department, EpiConsult Biomedical Consulting and Medical Communications Agency, Dover, UK

${ }^{3}$ Department of Epidemiology, Johns Hopkins University, Baltimore, Maryland, USA

${ }^{4}$ Urgent Care, Cayman Islands Urgent Care, George Town, Cayman Islands
\end{abstract}

Correspondence to Dr Gabor Zoltan Xantus, Alumni, Cardiff University, Cardiff CF10 3AT, UK; gabor. xantus@gmail.com

Received 4 March 2020 Revised 5 May 2020 Accepted 15 May 2020
Check for updates

(c) Author(s) (or their employer(s)) 2020. No commercial re-use. See rights and permissions. Published by BMJ.

To cite: Xantus GZ,

Gyarmathy AV, Johnson CA. Postgrad Med J

2020:96:686-692.

\section{ABSTRACT}

In the summer of 2019, the Center for Disease Control and Prevention (CDC) declared an emergency of electronic cigarettes and/or vaping (vaping)-associated lung injury (EVALI) in the USA. The outbreak abated by January 2020, which the CDC attributed to heightened public awareness, 'user actions to reduce risk' and potentially the removal of vitamin E acetate (VEA) from vaping products (VEA is an oily chemical cutting agent, strongly associated with the disease). Even though the EVALI outbreak appears to be over, numerous epidemiological and medical questions are left still open. First, why were there practically no cases outside the USA, which represents nearly a quarter of the global vaping market? Comparative studies to map the differences in device/fluids/user habits between countries might be needed urgently. Second, what is the pathomechanism that sickens vapers irrespective of VEA exposure? VEA was only confirmed in about half of the cases and the presumed toxicity is yet to be determined. Aetiology/ epidemiology focused research is needed to investigate/ interpret the broader context to explain the outbreak. Third, could any socioeconomic/environmental factors have influenced the course of the outbreak? Finally, what should we expect in the years to come? Was EVALI a serious but reversible emergency medicine condition or is vaping as detrimental to long-term health as smoking? Besides the complex legislative, regulatory, ethical aspects of EVALI, biomedical research is also difficult: in-vitro experiments have limited inferential value to real real-life vaping due to its complexity; user habits are selfreported and under-researched; there is an active black market pouring unknown quality counterfeit products and, in the USA, federal restrictions limit cannabis research. Vaping is a toxicological, multidimensional conundrum; therefore, stringent quality control, transparent legal/ethical boundaries, meticulous international research and user education are paramount to prevent potential future outbreaks and determine the parameters safe vaping (if these exist).

\section{BACKGROUND}

The Centers for Disease Control and Prevention (CDC) declared an emergency ${ }^{1}$ of electronic cigarettes or vaping-associated lung injury (EVALI) in the USA in the summer of 2019. The outbreak peaked in September, with almost 1000 patients hospitalised, and nearly 120 cases per one million emergency department visits. ${ }^{2}$ By January 2020, more than 2500 EVALI cases were reported $(56 \%$ confirmed and $44 \%$ probable) with 60 fatalities. ${ }^{1}$ The majority of patients with EVALI were admitted to hospitals with acute respiratory distress; however, most had constitutional and/or gastrointestinal symptoms as well (70\% and $80 \%$, respectively). A typical patient with EVALI was white, young man between 18 and 24 years of age and vaped multiple products. Altogether $82 \%$ of hospitalised patients with EVALI used liquids that contained any tetrahydrocannabinol (THC; 33\% reported using exclusively THC), and 57\% used any nicotine (14\% used exclusively nicotine). ${ }^{2}$

After establishing an association between vitamin $\mathrm{E}$ acetate (VEA) and EVALI, the CDC warned the public to refrain from vaping in general and using THC containing fluids in particular-especially if obtained from informal sources. The outbreak abated by January 2020, which the CDC attributed to heightened public awareness, 'user actions to reduce risk' and potentially the removal of VEA from vaping products. ${ }^{1}$

Even though the EVALI outbreak appears to be over in the USA, numerous epidemiological and medical questions are left still open. First, why were the reported cases geographically concentrated in the USA, despite the (ever increasing) popularity of vaping all over the world? To date, there is free access for all to vaping products via online stores like Amazon, Ali Express, Ali Baba (>8000 vape-related products in each site). Second, according to the Food and Drug Administration (FDA), VEA exposure was only confirmed in half of the reported cases, so what is the pathomechanism that sickens vapers irrespective of VEA exposure ${ }^{3}$ ? Third, as the presumed toxicity is yet to be determined, does EVALI have subtypes based on fluids/device and/or the frequency (number of daily puffs) with well-defined median exposure times and median lethal concentrations like other toxicological syndromes? To predict disease course/outcome associated with a given toxicant, concentrations and inhalation/ exposure must be determined (per Haber's rule or the reduced life expectancy model). ${ }^{4}$ Fourth, did the outbreak really stop because VEA was removed from vaping products, or in the context of the unprecedented surge and ebb of this vape-related syndrome, other potential non-medical causes (commercial factors, distribution channels, social media use, macroeconomy and microeconomy) need to be investigated as well? And finally, what shall we expect in the years to come? Was EVALI a serious but reversible emergency medicine condition or is vaping as detrimental to long-term health as smoking is? 
Table 1 Geographical and legislative characteristics of electronic cigarettes or vaping-associated lung injury (EVALI) case numbers as in December 2019

\begin{tabular}{|c|c|c|c|}
\hline & Fully legal & Medical use is legal & $\begin{array}{l}\text { CBD (<0.3\% THC) } \\
\text { only }\end{array}$ \\
\hline 200-249 cases & & Illinois & Texas \\
\hline 150-199 cases & $\begin{array}{l}\text { California, } \\
\text { New York }\end{array}$ & & \\
\hline 100-149 cases & & $\begin{array}{l}\text { Utah, Minnesota, } \\
\text { Pennsylvania Florida, } \\
\text { New Jersey, }\end{array}$ & Indiana \\
\hline 50-99 cases & $\begin{array}{l}\text { Connecticut, } \\
\text { Ohio } \\
\text { Michigan } \\
\text { Maryland }\end{array}$ & & $\begin{array}{l}\text { Virginia, Tennessee } \\
\text { Wisconsin, North } \\
\text { Carolina, lowa }\end{array}$ \\
\hline $10-49$ cases & $\begin{array}{l}\text { Washington, } \\
\text { Oregon, } \\
\text { Delaware }\end{array}$ & $\begin{array}{l}\text { New Mexico, Missouri, } \\
\text { Arkansas, North Dakota, } \\
\text { South Dakota Arkansas, } \\
\text { Louisiana, Arizona, West } \\
\text { Virginia }\end{array}$ & $\begin{array}{l}\text { Georgia, Kansas South } \\
\text { Carolina, Alabama } \\
\text { Nebraska, Idaho, } \\
\text { Mississippi }\end{array}$ \\
\hline$<10$ cases & $\begin{array}{l}\text { Colorado, } \\
\text { Alaska }\end{array}$ & $\begin{array}{l}\text { Nevada, Oklahoma, } \\
\text { Hawaii }\end{array}$ & Montana, Wyoming \\
\hline
\end{tabular}

CBD, Cannabidiol; THC, tetrahydrocannabinol.

\section{Epidemiological considerations}

Epidemiological investigations aim to identify patterns/potential causes to determine measures necessary to prevent further occurrences. The most obvious characteristic of the present EVALI outbreak was its territorial exclusivity. An endemic surge can be explained either with increase of a given disease or with differences in surveillance. Latter is unlikely given the fundamental similarities between the systematic collection/analysis/reporting of health data in the USA, UK and Australia ${ }^{5}$; hence, the outbreak can be considered genuine. There are, however, certain limitations to the EVALI-related epidemiological data.

Unfortunately, incidence/prevalence calculations might be unreliable, because on one hand hospital reporting was voluntary, and on the other hand vape use data were obtained mostly by self-reporting (which is probably unreliable in a potentially punitive legal environment) seldom crosschecked by urinary THC analysis. Moreover, cases/fatalities within the USA did not follow any clear geographical and/or legislative pattern (THC is outlawed in certain states but legal in others). See table 1. Another, and probably more important problem is that neither case definition nor the potential aetiology is straight forward: EVALI is a (surveillance-rather than clinical) diagnosis of exclusion and vaping is a blanket term covering a method of conveying heated aerosols to the lungs with a multitude of devices and/or substances and significant differences in user habits. As a typical patient with EVALI used multiple products, the exposure matrix is infinite. Vape fluids/pods are available in abundance, often with unknown ingredients: legally sold fluids are protected by trade secret, and counterfeit fluids or home-cooked 'juices' may obviously have completely unpredictable ingredients. The inhaled aerosols do not depend only on the fluids used but could significantly differ both in constitution and concentration of volatile/non-volatile substances if vaped via a different device (based on the voltage used and the material of the coil). Another, probably unaccounted variable is the fact that devices are often adulterated ('upgraded') to provide significantly different output than the manufacturer settings resulting in unpredictable physical-chemical characteristics.

The case definition is also difficult to interpret in the temporal context. EVALI case definition warrants the use of some sort of electronic vaping devices within 1-3 months of the onset of symptoms. Case definition with such prolonged latency would probably be keeping in with chronic toxicity rather than burst exposure to one (or more) highly toxic compounds. Should EVALI be the result of chronic exposure (even if the offending agent is withdrawn from vaping as the CDC suggested) case numbers would probably have dropped less suddenly as it was seen in October 2019 (see figure 1). ${ }^{1}$ The pattern of cases (steep increase and steep decline within 7 weeks) is probably more characteristic of acute poisoning rather than insidious toxicity, which is against the presumed 1-3 months latency. In-depth knowledge of the user habits (exposure times/pattern) and fluid/ device matrix is key to ascertain either option.

EVALI cases in the US 2019-2020

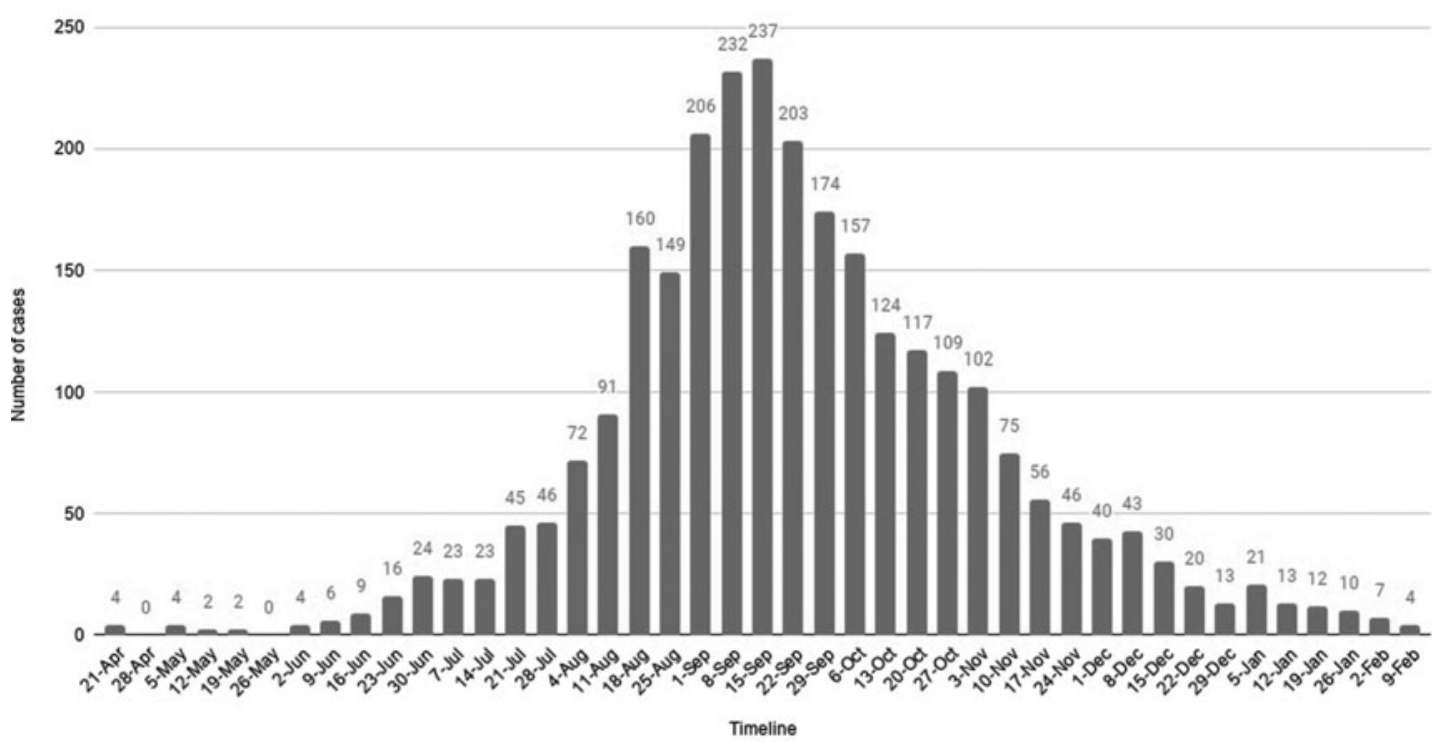

Figure 1 Hospital admission for patients with lung injury associated with e-cigarette use, or vaping -USA, 2019-2020. Data from the Centers for Disease Control and Prevention referring circular (https://www.cdc.gov/tobacco/basic_information/ecigarettes/severe-lung-disease.html). EVALI, electronic cigarettes or vaping-associated lung injury. 
Table 2 Legal status of cannabis and vaping in the world

\begin{tabular}{|c|c|c|}
\hline Country & $\begin{array}{l}\text { Legal status of } \\
\text { cannabis }\end{array}$ & Legal status of vaping \\
\hline Australia & $\begin{array}{l}\text { Medical cannabis is } \\
\text { legal }\end{array}$ & Vaping is unrestricted \\
\hline Arab language countries & Illegal & Illegal \\
\hline Brazil & $\begin{array}{l}\text { Medical cannabis is } \\
\text { permitted }\end{array}$ & $\begin{array}{l}\text { Vaping is illegal but medicinal use is } \\
\text { accepted (smoking cessation) }\end{array}$ \\
\hline China & Illegal & $\begin{array}{l}\text { Governmental ban on sales/marketing of } \\
\text { certain vapes and restricted use in public }\end{array}$ \\
\hline $\begin{array}{l}\text { Europe (country-specific } \\
\text { data in table 3) }\end{array}$ & $\begin{array}{l}\text { CBD with }<0.2 \%- \\
0.3 \% \text { THC is legal in } \\
\text { most countries }\end{array}$ & Vaping is unrestricted \\
\hline India & Cannabis is illegal & $\begin{array}{l}\text { Federal ban on the import, manufacture, } \\
\text { sale, advertisement, storage and } \\
\text { distribution of e-cigarettes }\end{array}$ \\
\hline Israel & $\begin{array}{l}\text { Cannabis is } \\
\text { decriminalised }\end{array}$ & Vaping is unrestricted \\
\hline Japan & Cannabis is illegal & $\begin{array}{l}\text { Vaping is illegal but medicinal use is } \\
\text { accepted (smoking cessation) }\end{array}$ \\
\hline Korea & $\begin{array}{l}\text { Medical cannabis is } \\
\text { permitted }\end{array}$ & Vaping is unrestricted \\
\hline Nigeria & Cannabis is illegal & \\
\hline South Africa & $\begin{array}{l}\text { Cannabis is } \\
\text { decriminalised }\end{array}$ & Vaping is unrestricted \\
\hline
\end{tabular}

THC, tetrahydrocannabinol.

\section{Cases outside the USA}

According to Euromonitor, well over 40 million people around the world are estimated to use some form of electronic cigarettes/vapes. China, Russia and the USA each have about 10 million users. ${ }^{6}$ EVALI, however, is seemingly endemic to North-America: over 2700 cases have been reported so far in the USA, 17 in Canada ${ }^{7}$ and one in Mexico $^{8}$ (latter was imported from the USA). There were significant differences between the Canadian and US cases though: contrary to the USA, $52 \%$ of the Canadian patients with EVALI vaped nicotine-only products (vs $13 \%$ in the USA, $p<0.0001$ ). In Canada, $23.5 \%$ used THC only (vs $35 \%$ in the USA, p $<0.0001$ ) and 'only' $82 \%$ of EVALI cases were hospitalised in Canada (vs 95\% in the USA, $\mathrm{p}<0.0001)$. Cannabis is fully decriminalised in Canada and access to it is more established/regulated rendering self-reported data probably more reliable.

To the best knowledge of the authors, there have been only nine EVALI cases reported outside the USA/Canada. To date, three cases have been reported in Brazil (allegedly all used vape juices from the USA), one case from Argentina and one from Ecuador. $^{9-11}$ There have been three cases in Asia: two from Thailand $^{12}$ and one from Israel. ${ }^{13}$ One Thai and the Israeli patients allegedly sourced their cannabinoid vapes from the USA. ${ }^{14}$ There has been only one case reported from Europe, with a vape fluid ordered from the USA. ${ }^{15}$ There have been no reports from Russia, where the vape market is similar to the USA in size and exposure although with less stringent control. ${ }^{16}$ There have been no cases reported from Australia and Africa. Interestingly, vaping is not so popular either in Asia or Africa and in the Americas (South, Central America including the Caribbean), where people traditionally tend to smoke dried cannabis. Also, there are significant regulatory/legal differences in both cannabinoids and e-cigarette/vaping use around the world (see table 2). ${ }^{17} 18$

Unfortunately, little is known about the content/constitution of the vape fluids in general and the ones used in the USA in particular. Internationally coordinated, standardised chemical/ analytical studies are needed to determine the difference in content of e-liquids/devices (between the USA and the rest of the world), and to understand the potential toxicological mechanisms of EVALI. More importantly, user habits need to be researched within and outside the USA, as frequency, the volume of inhaled puffs and the temperature of the different vapours/ aerosols might significantly alter exposure.

\section{Strong link between EVALI and VEA}

As early as September 2019, VEA was named as a primary suspect associated with this new respiratory syndrome. Both privately commissioned laboratories and the FDA's forensic laboratory both identified VEA in a variety of THC vape juices from both legitimate and illicit sources. ${ }^{19} 20$ However, the analysed samples were selected using convenience sampling, and most even without link to patients. Convenience sampling renders results vulnerable to selection bias increasing the likelihood of chance findings.

In one retrospective observational study, ${ }^{21}$ the CDC assessed both temporal and spatial concurrence of VEA and EVALI in Minnesota. After having analysed certain samples confiscated by the police and another batch linked to patients with EVALI, the CDC concluded that VEA was strongly associated with the outbreak, because VEA was not present in the vaping pods prior to 2019 and as the symptoms of EVALI were not reported prior to the present outbreak. Nevertheless, association (however strong) is not necessarily equals causation due to unobserved confounders. In this case, there were a few of those: selection bias due to convenience sampling (only a few vape pods were linked to patients, while others were seized by law enforcement) and numerous unaccounted factors: all samples were confiscated in 2018 , with no record of any potential ill health effects associated with their use, there were no data regarding either the storage conditions in police evidence lockers and/or the stability of VEA in open illicit vape/pods, and so on. Selection bias and unaccounted confounders render results vulnerable to type 1 error (false positive). The report has also questionable external validity: confiscated illicit samples from Minnesota (where medical cannabis is legal, recreational use is illegal) may not necessarily be inferential to the whole of the USA.

Three CDC reports confirmed the presence of VEA in vape pods linked to patients with EVALI (843 samples linked to 1090 patients, ${ }^{3} 677$ samples linked to 95 patients ${ }^{22}$ and 545 samples to 70 patients, ${ }^{23}$ respectively). However, the data regarding the

Table 3 Legal status of CBD (with $<0.2 \%-0.3 \%$ tetrahydrocannabinol) in European countries

\begin{tabular}{llllllllllll}
\hline Albania & Austria & Belarus & Belgium & Bosnia and Herzegovina & Bulgaria & Croatia & Cyprus & Czech & Denmark & Estonia & France \\
\hline No & Yes, ${ }^{*}$ & No & Yes* & No & Yes & Yes & Yes & Yes & No & Yes & Yes \\
Germany & Greece & Hungary & Iceland & Ireland & Italy & Lithuania & Luxembourg & Malta & Netherland & Norway & Portugal \\
Yes, $^{*}$ & Yes, & Yes & No & Yes & Yes & Yes & Yes & Yes* $^{*}$ & Yes & Yes & Yes* \\
Romania $^{*}$ & Russia & Serbia & Slovakia & Slovenia & Spain & Sweden & Switzerland & Ukraine & UK & Legal & Medical \\
Yes & No & No & No & Yes & Yes & Yes & Yes & Yes* $^{*}$ & Yes & 23 & 7 \\
\hline
\end{tabular}


VEA content were incompletely reported (no sample means, SD/ IQRs or CIs were published) rendering results/conclusions unreliable.

In a case series of 51 patients with EVALI $^{24}$ undergoing bronchoalveolar lavage (BAL), 48 BAL fluids (94\%) tested positive for VEA. The potential role of VEA in EVALI was presumed based on the fact that no VEA was detected in the BAL fluid of the comparator group. However, there were a few methodological errors in the study. First, the comparison was based on false equivalency: all control samples were obtained 1-3 years earlier from healthy individuals from Ohio, who vaped nicotine-only fluids (VEA exposure is unlikely). Furthermore, there are no data on VEA stability/detectability in biological samples after such a lengthy storage time. Second, BAL was performed at the discretion of the attending clinicians at various time points through the course of EVALI without reference/stratification to medical and medication history rendering results vulnerable to selection bias. Third, VEA in the BAL fluids was reported in a qualitative fashion (positive if above the level of detection and negative if under); however, without both the median toxicological dose or the median lethal exposure time, the inferential value of the intra-alveolar VEA is yet to be determined. Finally, the analysis was performed by isotope dilution mass spectrometry gas chromatography, however with no reference to the internal standards used. Without appropriate internal standards, VEA might have been mistaken with endogenous alveolar vitamin $\mathrm{E}$ (VE) due to possible redox interconversion of VE isomers. ${ }^{25} \mathrm{VE}$ is an important lipoid component of the surfactant. A previous prospective intensive care unit (ICU)-based clinical study reported elevated VE levels in BAL samples of patients with acute respiratory distress syndrome (ARDS) and/or acute lung injury (ALI) compared with healthy controls. ${ }^{26}$ Similar findings were reported comparing consecutive BAL samples of ventilated patients with ARDS: the worsening of the clinical symptoms was associated with increasing intra-alveolar VE levels. ${ }^{27}$ Both papers concluded that elevated alveolar VE levels might be seen as a part of the body's defence mechanism in ARDS.

The list of priority toxicants was set up by CDC without explaining the rationale. The presumed aetiological role of VEA is surprising for numerous reasons. Prior to EVALI, there had been no reports of VEA toxicity (or any of its biologically active derivatives like VE). During its 57 years career in the food and cosmetic industry, VEA has been considered a safe additive in a multitude of products with little to no adverse event reports in the context of either respiratory conditions or constitutional/gastroenterological symptoms. VEA is converted to the biological active VE by hydrolysis in various human tissues, and the conversion is accelerated by oily vehicles like vegetable oil. The oral/transdermal bioavailability of VEA to VE is $1: 1.36-2 .{ }^{28}$ To the best of our knowledge, intrapulmonary bioavailability has not been studied. However, there have been numerous animal and human studies investigating various VE isomers in different respiratory inflammatory conditions administered either via oral/parenteral route direct intrapulmonary fashion (nebulised/earosoled). No significant benefit was demonstrated, but more importantly no harm either. ${ }^{29}$

\section{The CDC claims that EVALI outbreak might have ceased as (VEA) was removed from the products? If so, how was it achieved?}

The CDC concluded that the heightened awareness and risk averse user behaviour might have prompted the removal of VEA from the vape juices. News regarding EVALI dominated both mass and social media for months, so one may assume that the CDC warning ('do not use THC-containing e-cigarette, or vaping, products, especially those acquired from informal sources such as friends, family members, or from in-person or online dealers') probably reached the target audience. Self-reported data suggest that $78 \%$ of vape fluids (linked to patients with EVALI) were obtained from informal sources.

However, the distribution of EVALI cases over time and the demographic features of the target group (mostly young white men who usually have strong social media presence) may suggest a nationwide coordinated retail campaign rather than home cooking or informal merchandising. Such centralised campaign would require either a well-branded commercial chain (no such outlets were identified) or digital marketing campaign with a strong message to boost online sales (like price promise or high quality).

The cannabinoid black market is estimated to be at least double the legal market due to heavy taxation, variable legislation and different user habits. The low price, easy accessibility, favourable toxicological profile, high viscosity, lack of odour and amber colour of VEA made it an ideal agent to cut THC vape oils with. Interestingly, some of the online retail sources have disappeared immediately after the CDC named the three most frequently identified counterfeit products. Unfortunately, there was neither detailed chemical nor user habit analysis reported in relation to the bootleg brands, so the inferential value of counterfeit products to the clinical course is yet to be determined.

Increased scrutiny/user awareness might well have changed production in home cooking/illicit laboratories resulting in the withdrawal of VEA or any other previously unknown cutting agents from the market. Alternatively, VEA could have been depleted due to national shortage, although it is unlikely given the excessive need in cosmetic/food industry. However, product withdrawals are not easy if goods are distributed through multitude of commercial channels rather than one central plant. VEA would have been difficult to withdraw from the market in no time if marketed via conventional channels.

To date, there have been no studies published analysing potential changes in user habits after the EVALI outbreak. Consequently, nobody can assess the actual effectiveness of awareness campaigns on risk avoidance in EVALI. Health awareness campaigns take weeks to months to significantly change user habits, ${ }^{30}$ and therefore the observed heightened awareness (and consequent risk averse) is unlikely to be the main cause of the sudden drop in cases.

\section{Economy context of the EVALI outbreak}

One can also observe a temporal coincidence between the surge and ebb of EVALI cases and the trade war with China. The initial reports of a cluster of concerning lung condition surfaced first in April 2019 shortly after the Trump administration launched threats to Chinese import. China has been the largest exporter of both vape devices and vape fluids/ingredients to the USA. Interestingly, EVALI cases started to ebb in October, when the trade agreement was sealed. Such a major threat on supply might have forced domestic producers to find alternative sources.

As a response to increasing popularity of vaping among the young, in September 2019 (when the EVALI outbreak peaked) the Trump administration announced a proposed ban on all flavoured e-cigarettes. A similar ban was introduced a decade ago on flavoured cigarettes resulting in a 6\% drop in youth consumption of any form of tobacco. ${ }^{31}$ Smoking-related morbidity/mortality may justify such measures, since over 34 million adults smoke currently cigarettes in the USA with 480000 smoking-related death per year. To date, 60 succumbed to EVALI out of 10 million or so vapers. However, in the wake of the EVALI 
outbreak, fear of bans/restrictions might have triggered mass sales at discounted prices to prevent future losses.

Both the vaping and the cannabis industry faced interesting times in 2019. At the moment, there is no federal tax on vapour products. Nicotine vape fluids are momentarily taxed by volume, but due to a loophole, vape fluids are tax exempt if sold with a device. ${ }^{32}$ The House Ways and Means Committee approved the bipartisan bill (HR 4742) in October that would tax e-cigarettes/vapes bringing US $\$ 1.01$ federal levy per pack of cigarettes on tobacco alternatives 334 to compensate the forecasted a steep decrease in tobacco tax revenues (up to 12.69 billion dollars by 2024). ${ }^{35}$ Bundle deals are commonplace in commerce to optimise taxation, and an attractive deal (eg, a given device with vape juice of the customer's choice or vice versa) at tax-free prices might well attracted huge interest among the price sensitive college students. Interestingly, the ebb of cases coincided with the signing of the new legislation.

Despite the alarming potential connection between vaping THC derivatives and EVALI, cannabis commercialisation/legalisation has not been halted anywhere in the USA not even in Illinois, where the outbreak started and had one of the highest tolls. In November 2019, the Illinois General Assembly ratified a bill to legalise the sales of recreational cannabis hoping to generate 2-4 billion in taxes in a few years' time. ${ }^{36}$ Legislators seemed to have realised that cannabis use cannot be stopped by outlawing marijuana, but decriminalisation might bring in significant tax revenues similarly to alcohol and tobacco. Another example is California, which collected over US\$1 billion in tax revenues in 2018-2019 from the cannabis industry. It does not seem to be enough: a bill signed in October increased the excise tax with 15\% effective from January 2020. ${ }^{37}$ Tax increases would make black market inevitably more attractive in the Golden State, where illegal sales already nearly tripled the legitimate market in 2019 (8.7 billion vs 3.1). Bootleggers are for profit over quality; it is fairly idealistic to believe that a thriving black market might introduce quality control measures to respect any health-related concerns.

There is one thing in common across the US states: commercial, legal and tax sanctions in 2019 resulted significant price increase in cannabinoids favouring the influx of low quality, cheap products of illicit sources. Socioeconomic status is knowingly inversely associated with risk avoidance, and morbidity/ mortality of non-communicable diseases. ${ }^{38}$

\section{What caused EVALI then?}

Despite numerous in vitro, animal and human studies, little is known about the short-term and long-term ill effects of the increasingly popular vaping. One of the presumed pathomechanisms might be repeated exposure to metal fumes. Most devices use rechargeable batteries of 3-6 V to heat a metal coil (up to $1000^{\circ} \mathrm{C}^{\circ}$ ), well above the boiling points of certain harmful metals (cadmium, zinc, etc). Hence, it is not surprising that vape aerosols demonstrated to contain heavy metal residue significantly exceeding current health-based limits. ${ }^{39}$ Coil alloys are produced at the discretion of the manufacturers, and their manufacturing is probably driven by cost effectiveness rather than toxicological concerns.

Some hypothesised the formation of new molecules during thermal activation/pyrolysis. Previous reports mentioned fungicide contaminants as well, which will turn into cyanide containing chemicals when heated. ${ }^{40} \mathrm{~A}$ recent in-vitro experiment documented the formation of ketene when vaping VEA. ${ }^{41}$ Ketene is a highly toxic gas with similar toxicological profile than phosgene, and therefore theoretically it could have explained the syndrome of lung injury, constitutional and gastroenterological symptoms seen in EVALI. However, latter in vitro data may not be applicable to the present outbreak, because on one hand only one European device was tested (which might have a different thermal range than devices used in the USA) and the other hand the experimented e-liquid was $100 \%$ pure VEA oil (illicit pods contained between $23 \%$ and $88 \% \mathrm{VEA})$. Interestingly, the only report of chronic industrial ketene exposure did not mention any constitutional/ gastrointestinal symptoms during either the emergency room or ICU treatment ${ }^{42}$ so this theory might need further research. The corresponding investigator of the case report was contacted for clinical details via email.

Vaping is the new bogeyman. It is undeniable that both nicotine and cannabinoid vapours contain harmful chemicals. ${ }^{43} 44$ However, in contrast to vaping, smoking-related direct and indirect costs in the USA exceeded US $\$ 300$ billion $^{38}$ with 3.4 times as many smokers as vape users. As most smoking-related ailment develops insidiously, longitudinal studies are needed to determine the vaping-related health effects and related medical costs. Given the fact that vaping is far more complex toxicologically than smoking, a slow increase in medical vape-related conditions may not be completely surprising in the years to come.

\section{Difficulties in research}

Besides some complex problems in legislation, regulation and ethics, research is also not easy in this field. In-vitro experiments have limited inferential to real-life vaping. On one hand, most models capture $40-60 \mathrm{~mL}$ samples of heated aerosols at $5-15 \mathrm{~cm}$ from the heat source using a cold chamber technique. Such models significantly differ from the bronchial/alveolar milieu in either temperature or humidity; therefore, measured experimental levels/concentrations of volatile and/or non-volatile components might be very different from levels/concentrations in the actual small airways during exposure. A recent animal model demonstrated similar pulmonary histological findings in mice exposed to $88 \%$ VEA aerosol, as seen in patients with EVALI. ${ }^{45}$ This might be an important step to understand the pulmonary pathology of EVALI; however, rodent models tend to have limited validity in modelling human ARDS/ALI. ${ }^{46}$ Also, as most other experiments, this was also carried out using one particular vaping device. Reallife users typically use multiple device/fluids (in 2014 over 460 vape brands were sold in the USA) with significant variability in voltage, resistance, coil material and lifespan, vape fluids, and so on, which significantly limit the applicability of singe-device studies. ${ }^{47}$ Last but not least the US federal restrictions on cannabis research thin research resources both in funds and manpower.

\section{CONCLUSION}

The epidemiology of EVALI is very complex, and its (probably multifactorial) aetiology is yet to be determined. The CDC established a strong association between VEA and EVALI, but there were methodological flaws in the underpinning studies rendering results potentially vulnerable to type 1 error. No plausible toxicological model of causation has yet been developed to predict organ damage or disease progression (as neither minimal/median toxic concentration of alveolar VEA levels and minimum/median exposure time were established), necessitating further research of user habits. The FDA has clear regulations regarding legally sold vape fluids, but counterfeit/home-cooked vape juices supply users with products of unknown physical-chemical and/or toxicological properties. However, vape devices are not stringently regulated adding potential serious uncontrolled variables into the complex picture. Researchers should keep an open mind when looking for 
causation considering further unobserved confounders given the cultural/socioeconomical characteristics of this demographic group. Neither in-vitro nor qualitative research is fully reliable given the complexity of vaping and the potential punitive legal environment is some states. Until detailed patient-level analysis is performed in this cohort regarding devices, vape juices and user habits (the latter controlled for potential recall bias), the exact pathomechanism of EVALI probably remains unknown.

Vaporised liquids-should they be counterfeit or legitimateshare only one thing in common: nobody knows exactly what

\section{Main messages}

- In the summer of 2019, the Center for Disease Control and Prevention declared an emergency of electronic cigarettes and/or vaping (vaping) associated lung injury (EVALI) in the United States. Even though the EVALI outbreak appears to be over, numerous epidemiological and medical questions are left still open. Firstly, why were there practically no cases outside the USA. Secondly, what is the pathomechanism that sickens vapers? Finally, what should we expect in the years to come?

- Vaping is a toxicologic, multidimensional conundrum therefore, stringent quality control, transparent legal/ethical boundaries, meticulous international research and user education is paramount to prevent potential future outbreaks and determine the parameters safe vaping (if these exist).

\section{Current research questions}

- Comparative studies to map the differences in device/fluids/user habits between countries might be needed urgently?

- Because VEA was only confirmed in about half of the cases and the presumed toxicity is yet to be determined. Aetiology/epidemiology focused research is needed to investigate/interpret the broader context to explain the outbreak?

- Could any socioeconomic/environmental factors have influenced the course of the outbreak? Qualitative studies are needed to assess vaping habits before and after the outbreak to identify major changes potentially contributing to the ebb of cases?

- Meticulous, physical-chemical international research is needed to assess safety of vape fluids and devices alike?

\section{Key references}

1. Outbreak of Lung Injury Associated with the Use of E-Cigarette, or Vaping, Products. 2020. The Centre for Disease Control and Prevention. [Online] Available at: https://www.cdc.gov/tobacco/ basic_information/e-cigarettes/severe-lung-disease.html

2. Connell DW, YO Q, Verma V. Influence of exposure time on toxicity-An overview. 2016. Toxicology. [Online] Available at: https://www.sciencedirect.com/science/article/pii/ S0300483X16300695

3. Blount B, Karwowski M, Shields PG, et al. Vitamin E Acetate in Bronchoalveolar-Lavage Fluid Associated with EVALI. NEJM 2019. [Online] Available at: DOI:10.1056/NEJMoa1916433

4. Lodge JK. Vitamin E bioavailability in humans. J Plant Physiol 2005;162(7):790-6

5. Xantus GZ Vaping-associated lung injury-VALI facts, assumptions and opportunities: review of the present situation. 2019. Postgrad Med J. doi: 10.1136/postgradmedj-2019-137185

\section{Self assessment questions}

1. What are the main epidemiological concerns of electronic cigarettes or vaping-associated lung injury (EVALI)?
A. The endemic nature of the outbreak.
B. Incidence/prevalence calculations might be unreliable, because on one hand hospital reporting was voluntary.
C. Vape use data were obtained mostly by self-reporting.
D. The case definition is vague.

2. What evidence pointed towards association with vitamin E acetate (VEA)?

A. Presence of VEA in cannabinoid vape pods.

B. Absence of VEA in samples confiscated prior to 2019.

C. Presence of VEA in bronchoalveolar fluids of patients with EVALI.

D. Absence of VEA in bronchoalveolar fluids of healthy individuals.

3. What are the pitfalls of retrospective evidence?
A. Convenience sampling.
B. False equivalency.
C. Inappropriate measurements.

4. What are the most important non-medical factors of an outbreak?
A. Legal versus unregulated commercial channels.
B. User education/communication with the public.
C. Best practice sharing with the wider community.

5. What are the most plausible causes of EVALI?
A. Yet to be determined.
B. Unregulated vaping devices with variable pfysical-chemical parameters.
C. Illicit/adulterated liquids with unknown aerosols.

users inhale when they activate their device. Vaping is a toxicological, multidimensional conundrum. Therefore, to identify culprit/culprits is similar to finding a needle in the haystack. Stringent quality control, transparent legal/ethical boundaries, meticulous international research and user education might be needed to prevent similar outbreaks and determine safe vaping.

Contributors GZX incepted the idea, carried out the research necessary and prepared the first draft. AVG reviewed the first draft and recommended changes in the concept to shape the final draft. CAJ shaped the discussion/conclusion and proofread the final version.

Funding The authors have not declared a specific grant for this research from any funding agency in the public, commercial or not-for-profit sectors.

\section{Competing interests None declared.}

Patient consent for publication Not required.

Provenance and peer review Not commissioned; externally peer reviewed.

\section{ORCID iD}

Gabor Zoltan Xantus http://orcid.org/0000-0003-3060-0069

\section{REFERENCES}

1 Outbreak of Lung Injury Associated with the Use of E-Cigarette, or Vaping, Products. 2020. The Centre for Disease Control and Prevention. [Online]. Available: https:// www.cdc.gov/tobacco/basic_information/e-cigarettes/severe-lung-disease.html

2 Krishnasamy VP, Hallowell BD, Ko JY, et al. Update: Characteristics of a Nationwide Outbreak of E-cigarette, or Vaping, Product Use-Associated Lung Injury - United States, August 2019-January 2020. MMWR Morb Mortal Wkly Rep 2020;69:90-4.http:// www.ncbi.nlm.nih.gov/pubmed/31971931

3 Lung Injuries Associated with Use of Vaping Products Information for the Public, FDA Actions, and Recommendations. 2020. The Food and Drug Administration. [Online]. Available: https://www.fda.gov/news-events/public-health-focus/lung-injuriesassociated-use-vaping-products 
4 Connell DW, YO Q, Verma V. Influence of exposure time on toxicity-An overview. 2016. Toxicology. [Online]. Available: https://www.sciencedirect.com/science/article/ pii/S0300483X16300695

5 Surveillance systems evaluation: a systematic review of the existing approaches. 2015 BMC Public Health [Online].

6 Euromonitor. Smokeless tobacco and vapour products, 2020. Available: https://www .euromonitor.com/smokeless -tobacco-and-vapour-products

7 Vaping-associated lung illness. health Canada, 2020. Available: https://www.canada. ca/en/public-health/services/diseases/vaping-pulmonary-illness.html

8 Macias AE, Garcia FJ, Saldana SG. A patient from Mexico with vaping-associated lung injury, seizures and renal failure. Tob Induc Dis 2019;17:eCollection 2019. doi:10.18332/tid/114316 http://www.ncbi.nlm.nih.gov/pubmed/31892921

9 Por que a redução de danos não é indicada para o controle do tabagismo. Sociedade rasiliera de Pulmonolgia a Tisiologia, 2019. Available: https://sbpt.org.br/portal/t/evali/

10 Loewy MA. EVALI: sendos casos de lesiones pulmonares por vaping en Argentina y Ecuador despiertan preocupación en Latinoamérica. MEDSCAPE, 2019. Available: https://espanol.medscape.com/verarticulo/5904675

11 Boloña E, Felix M, Vanegas E, et al. A case of Vaping-associated pulmonary illness in South America: highlighting the need for awareness and surveillance programs in the region. Am J Respir Crit Care Med 2020;201:733-5.http://www.ncbi.nlm.nih.gov/ pubmed/31810372

12 National Institute of health of Thailand, 2020. Available: http://nih.dmsc.moph.go.th /indexeng.html

13 Ministry of health of the state of Israel, 2020. Available: https://www.health.gov.il/E nglish/Pages/HomePage.aspx

14 An imported case of e-cigarette or vaping associated lung injury (EVALI) in Barcelona.

15 Gambaryan M. P, Kalinina A, et al. Exposure of electronic cigarettes in Russia: results from Russian tobacco control policy evaluation study. Eur Resp J 2018.

16 Where is cannabis legal. Leafly, 2020. Available: https://www.leafly.com/news/canna bis-101/where-is-cannabis-legal

17 Glantz SA, Bareham DW. E-Cigarettes: use, effects on smoking, risks, and policy implications. Annu Rev Public Health 2018;39:215-35.http://www.ncbi.nlm.nih.gov/ pubmed/29323609

18 Vitamin E Acetate report. CannaSafe laboratories, 2019. Available: https://csalabs.com /wp-content/uploads/2019/10/CannaSafe VitaminEAcetate_Report.pf

19 Flora research laboratories, 2019. Available: http://www.floraresearch.com pdf

20 Taylor J, Wiens T, Peterson J, et al. Characteristics of e-cigarette, or Vaping, products used by patients with associated lung injury and products Seized by law enforcement - Minnesota, 2018 and 2019. morbidity and mortality Weekly report. The CDC;68:1096-100.

21 Lu D, Yang Y, Wu X, et al. Simultaneous determination of eight vitamin E isomers and $\alpha$-tocopherol acetate in functional foods and nutritional supplements by gas chromatography - mass spectrometry. Analytical Methods 2015;7:3353-62.

22 Lozier MJ, Wallace B, Anderson K, et al. Update: Demographic, Product, and Substance-Use Characteristics of Hospitalized Patients in a Nationwide Outbreak of E-cigarette, or Vaping, Product Use-Associated Lung Injuries - United States, December 2019. MMWR Morb Mortal Wkly Rep 2019;68:1142-8.http://www.ncbi.nlm.nih.gov/ pubmed/31830008

23 Blount BC, Karwowski MP, Shields PG, et al. Vitamin E acetate in Bronchoalveolar-Lavage fluid associated with EVALI. N Engl J Med 2020;382:697-705.http://www.ncbi.nlm.nih.gov/pubmed/31860793

24 Lu D, Yang Y, Wu X, et al. Simultaneous determination of eight vitamin E isomers and $\alpha$-tocopherol acetate in functional foods and nutritional supplements by gas chromatography - mass spectrometry. Anal. Methods 2015;7:3353-62.

25 Scmiedt R, Luboienski P, Markart C, et al. Alveolar antioxidant status in patients with acute respiratory distress syndrome. Eur Respirat J. Available: https://erj ersjournals.com/content/24/6/994

26 Ziai S, Jamaati H, Hajimodi M, et al. The relationship between vitamin E plasma and BAL concentrations, SOD activity and ventilatory support measures in critically ill patients. Iraj J Pharm Res 2014;0:953-60.

27 Lodge JK. Vitamin E bioavailability in humans. J Plant Physiol 2005;162:790-6.http:// www.ncbi.nlm.nih.gov/pubmed/16008106
28 Wilkinson M, Hart A, Milan S. Vitamins C and E for asthma and exercise-induced bronchoconstriction. Cochrane systematic reviews., 2014. Available: https://www .cochranelibrary.com/cdsr/doi/10.1002/14651858.CD010749.pub2/full

29 Wakefield MA, Loken B, Hornik RC. Use of mass media campaigns to change health behaviour. The Lancet 2010;376:1261-71.

30 Influence of the flavored cigarette ban on adolescent tobacco useGet rights and content. Available: https://doi.org/10.1016/j.amepre.2016.11.019

31 How high are vapor excise taxes in your state? 202. Available: https://taxfoundation .org/state-vapor-taxes-2019/

32 Protecting American Lungs Act of. Congress.gov, 2019. Available: https://www .congress.gov/bill/116th-congress/house-bill/4742

33 Tobacco tax revenue and forecast in the United States from 2000 to 2024. Statista, 2019. Available: https://www.statista.com/statistics/248964/revenues-from-tobaccotax-and-forecast-in-the-us/

34 Economic Trends in Tobacco. The centers for disease control and prevention, 2019. Available: https://www.cdc.gov/tobacco/data statistics/fact_sheets/economics/econ_ facts/index.htm

35 Cannabis Regulation and Tax Act. Illinois General assembly, 2019. Available: http:// ilga.gov/legislation/101/hb/10100hb1438sam002.htm

36 California department of Tax and fee administration, 2020. Available: https://www cdtfa.ca.gov/

37 s S, Carmeli C, Jokela M, et al. Socioeconomic status and the $25 \times 25$ risk factors as determinants of premature mortality: a multicohort study and meta-analysis of 1.7 million men and women. The Lancet [Online], 2017. Available: https://www ncbi.nlm.nih.gov/pmc/articles/PMC5368415

38 Olmedo P, Goessler W, Rule M, et al. Metal Concentrations in e-Cigarette Liquid and Aerosol Samples: The Contribution of Metallic Coils. Envir Health Perspectives [Online] Available: https://www.ncbi.nlm.nih.gov/pmc/articles/PMC6066345/

39 Xantus GZ. Vaping-associated lung injury-VALI facts, assumptions and opportunities: review of the present situation. Postgrad Med J 2020;96:61-63. doi:10.1136/postgradmedj-2019-137185 http://www.ncbi.nlm.nih.gov/pubmed/31767670

40 Wu D, O'She D. Potential to release of pulmonary toxic ketene from vaping pyrolysis of Vita min E acetate. 2019 ChemRxiv. [Online]. Available: https://chemrxiv.org/articles/ Potential_for_Release_of_Pulmonary_Toxic_Ketene_from_Vaping_Pyrolysis_of_Vit amin E Acetate/10058168

41 Huang J-F, Zhu D-M, Ma J-F, et al. Acute respiratory distress syndrome due to exposure to high-concentration mixture of ethenone and crotonaldehyde. Toxicol Ind Health 2015;31:585-7.http://www.ncbi.nlm.nih.gov/pubmed/23448861

42 Meehan-Atrash J, Luo W, McWhirter KJ, et al. Aerosol gas-phase components from cannabis e-cigarettes and Dabbing: mechanistic insight and quantitative risk analysis. ACS Omega 2019;4:16111-20.http://www.ncbi.nlm.nih.gov/pubmed/31592479

43 Vreeke S, Peyton DH, Strongin RM. Triacetin enhances levels of acrolein, formaldehyde hemiacetals, and acetaldehyde in electronic cigarette aerosols.. ACS Omega 2018;3:7165-70.http://www.ncbi.nlm.nih.gov/pubmed/30087908

44 Bhat TA, Kalathil SG, Bogner PN, et al. An animal model of inhaled vitamin E acetate and EVALI-like lung injury. N Eng/ J Med 2020;382: 1175-1177:1175.h ttp://www. ncbi.nlm.nih.gov/pubmed/32101656

45 Yehya N. Lessons learned in acute respiratory distress syndrome from the animal laboratory. Ann Trans/ Med 2019;7:503.http://www.ncbi.nlm.nih.gov/pubmed/31728356

46 Zhu S-H, Sun JY, Bonnevie E, et al. Four hundred and sixty brands of e-cigarettes and counting: implications for product regulation. Tob Control 2014;23 Suppl 3:iii3-9. http://www.ncbi.nlm.nih.gov/pubmed/24935895

48 The health effects of cannabis and cannabinoids: the current state of evidence and recommendations for research. Chapter 15 . challenges and barriers in conducting cannabis research. 2017. The National academies of sciences, engineering and medicine. Available: https://www.ncbi.n/m.nih.gov/books/NBK425757/

Answers

All of the above are true for all five questions. 